\title{
The effect of knowledge of reversibility on the reversibility of ambiguous figures
}

\author{
JOEL J. GIRGUS, IRVIN ROCK, and RAY EGATZ \\ Institute for Cognitive Studies, Rutgers, The State University, Newark, New Jersey 07102
}

\begin{abstract}
The role of knowledge of the reversibility of reversible figures was tested in four experiments. Two ambiguous figures, the vase-face figure and a depth-reversing pyramid-hallway figure were shown to high school students. In the Uninformed condition, subjects were not told that the figures were reversible. A sampling procedure was used in which subjects reported what they perceived at 5-sec intervals. Viewing durations of up to $3 \mathrm{~min}$ were used, and approximately half of all subjects did not reverse at all during the Uninformed condition, whereas virtually all subjects reversed quickly and frequently once they knew that the figures were reversible. These results are not consistent with neural fatigue models of perceptual reversal.
\end{abstract}

Ambiguous figures and the perceptual alternations which occur when viewing them are of interest because their explanation would appear to require central dynamic factors. Previous reports and theories have repeatedly stressed the spontaneous character of the reversals in which voluntary control neither causes nor prevents reversal. This apparent spontaneity of reversals has played an important role in the theoretical interpretation of the phenomena. The most widely investigated theory, the cortical satiation theory of Köhler and Wallach (1944), proposed that cortical events produce their own resistance and bring about their automatic replacement by the opposing cortical events that then result in the perceptual reorganization. But all fatigue or satiation theories of reversal, including those based on contemporary neurophysiological constructs, posit an inexorable effect due to continuous passive stimulation.

This kind of theory of reversal implicitly defines ambiguity purely in stimulus terms. The stimulus can represent two (or more) possible objects, and when one such percept is satiated another automatically replaces it. Of course, this presupposes that the observer can identify these alternatives either because each is a familiar object (e.g., "cube," "face," "vase," etc.) or because each is a member of a different category or distinctive in some way in the observer's repertoire (e.g., "cube tipped up or on edge," "two-dimensional line pattern," etc.) But one might ask the further question of whether the meaning of ambiguity presupposes awareness by the observer that the figure is ambiguous. This is the issue with which we are concerned here. There is nothing in the literature to suggest that such awareness is part of the meaning of ambiguity and, in fact, it seems to be implicit that such knowledge is not a necessary part of the meaning. Certainly such an assumption is alien to the satiation model for the reasons suggested above.

Nonetheless, experiments on figure reversal are performed with informed subjects. The method typically employed in studying this problem seems necessarily to entail informing the subject about the possible alternative perceptions of a given figure, and that the figure reverses. It is understandable why investigators have believed that only in this way can the subject be alerted to respond whenever a reversal occurs. However, such instructions may have the effect of playing a causal role, or of facilitating reversal and, if so, may seriously modify the very facts about figure reversibility.

For example, if the reversibility of the Necker cube is under study, the procedure typically entails explaining that the figure reverses its perspective, and then the experimenter makes certain that the subject can see and identify each of the two perspectives. Each alternative perspective is then identified by a label such as "up" or "down"; the subject then presses an appropriate button, depending upon what he ir she is perceiving. While this method certainly seems necessary and desirable in order to obtain data concerning the number of reversals and reversal latencies over a period of time, it has not been appreciated that it may also affect the outcome. Knowing that a figure is reversible, and what the alternative percepts are, may be a determinant of the reversal. On the other hand, if, as indicated in previous research, the reversals are indeed spontaneous and based on some process such as neural fatigue or satiation, then they should occur even without knowledge of the potential reversibility of the figure. If reversals are spontaneous, then knowledge of reversibility should be irrelevant.

To investigate this question, it was necessary to devise a new method whereby reversals would be reported but without the subject's being informed of the reversibility of the figure, or that the reporting of reversals was the actual concern of the experiment. 


\section{EXPERIMENT 1}

\section{Method}

The uninformed condition. The basic plan in this and the subsequent experiments was to prepare the subject, by first presenting a series of other figures, to describe what he or she was perceiving whenever the experimenter signaled by tapping a pencil. This sampling of the subject's perception by signals occurred at 5 - sec intervals and thus can be assumed to represent, with a high degree of accuracy, his or her perceptual experience throughout the entire exposure period. Moreover, a further careful interview following the exposure period probed the possibility that a reversal might have occurred between signals and therefore missed being reported, or that reversals occurred at any time during the exposure that were not reported for one reason or another.

But the essence of the method is not so much the sampling procedure per se, which has been used by other investigators in conjunction with the typical "informed" method, but rather the instructions and set created by the preparation figures. There were two such figures, shown to all subjects in all of the experiments. The first was an equilateral triangle $3 \frac{1}{4}$ in. on a side. The subject was instructed as follows: "This is an experiment in perception. It is not any kind of intelligenee test. 1 am going to show you cards with drawings on them. Please keep your eyes on the card at all times. When you first see the card, I want you to tell me what figure you see. In other words, if I were the subject in this experiment and I were looking at this card, I might say, 'triangle.' So it might go like this: I see the card: I say 'triangle,' and so on."

There then followed the second preparatory figure, which consisted of two isosceles triangles, a large one, with a 2 -in. base and $2 \frac{1 / 4}{-i n}$. sides, and a small one, with a 1 -in. base and $11 / 4$ in. sides, arranged in the shape of an hourglass, with the smaller triangle on top. The experimenter in displaying this card said: ' Here I might see two triangles or I might see an ' $\mathrm{X}$ ' or some other figure. By this, however, I do not mean what the drawing reminds you of. I am only interested in exactly what you see. So, if I saw this card, I might say ' $\mathrm{X}$ ' or 'two triangles' or ' $\mathrm{Xs}$ ' or whatever figure I now saw. So it might go like this. I see the card and I say 'two triangles.' The pen taps and I would say 'two triangles,' and so on. Or it might go like this. I see the card and I say ' $X$.' Then a moment later I might see two triangles instead of an X; therefore, when the pen taps I would say 'two triangles.' All of this depends on what I actually see on the card when I first saw it and each time the pen taps."

As a result of this preparation, the subject understood that he/she was to report what he/she perceived at each signal and that this report could conceivably differ from signal to signal. It was assumed that these instructions would elicit reports of reversal if they should occur with the critical figures that followed. However, the subject did not know that the critical figures were reversible and therefore he/she also did not know what the alternative perceptions were. If the subject asked questions indicating a lack of comprehension concerning any procedure, the instructions were repeated. Answers to other types of questions were delayed until the end of the experiment.

After the two preparatory figures were used to demonstrate the instructions, the experimental sequence was begun. The first three figures in this sequence were line drawings (all lines constituting all geometric figures drawn on cards used in the experi-

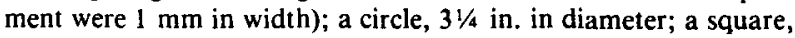
$31 / 4$ in. on a side; and a "snowman" type of figure consisting of one small circle, 1-3/8 in., on top of a larger circle, $1-3 / 4 \mathrm{in}$. in diameter, similar to the two used in the instruction sequence. The first three cards were each exposed for $15 \mathrm{sec}$, requiring an initial tap and three subsequent signals. In the first experiment, the fourth and fifth figures in the experimental sequence were the Rubin vase-face figure la white vase, $23 / 4$ in. across the top and
1-1/8 in. across the base, centered in a black background 2-3/8 in. wide and extending from the top to the bottom of the card (i.e., $31 / 2$ in.); the figure was centered on a white card as were all other figures] and the Necker cube, 2 in. on a side. For half of the subjects, the vase-face was the fourth figure, while the Necker cube preceded the vase-face for the other half of the subjects. Each of these critical figures was exposed for $30 \mathrm{sec}$ during the experiment, resulting in one signal at the outset, plus six more signals at $5-\mathrm{sec}$ intervals. When the viewing period for a given card was completed, it was placed face down on the desk and the subject immediately saw the next card in the series. The stimuli were presented to the subject drawn on 6 " $\times 3 \frac{1}{2}$ " white cards under conditions of normal room lighting. The subjects sat $3 \mathrm{ft}$ directly in front of the stimuli, which were held vertically perpendicular to a desk top by the experimenter. All responses were recorded on tape and subsequently transcribed.

Interview. After the initial sequence of responses during the Uninformed condition, the subject was interviewed. The interview procedure was designed to ascertain if a perceptual reversal of any sort had occurred without having been reported during the sampling procedure. During the interview, the subject was shown the ambiguous figure and the unambiguous versions of the two alternatives. If, during the experiment, the subject had re-. ported seeing only one alternative, he was now asked if he had seen both alternatives or only the one that he reported.

If the subject reported that he/she had seen something like the unreported alternative (i.e., did see the faces but had not said so), he/she was then arbitrarily scored as having reversed on the first signal and on all subsequent signals. Similarly, if the subject reported a reversal to a percept other than the two standard alternatives (i.e., Necker cube to "two squares"), this was scored as a reversal. These criteria overestimate the reversal rate and do so especially for the naive condition. Those subjects who skipped no more than two times in Experiments 1, 2, and 3 and no more than four times in Experiment 4 in either condition are included in the data. If, while making his responses to the stimuli and/or during the interview, a subject was identified as a nonreverser, all skips were counted as nonreversing trials. If a subject was identified as a reverser, all skips were treated as reversals.

The reversal data produced during the interview were considered to be of great importance and were treated on a par with the responses obtained during the exposure period.

In the interview, the subject was now required to be able to clearly see and describe both alternatives to the ambiguous figure. Thus the interview was also intended to make the subjects fully informed as to reversibility, and in this way was comparable to the procedure normally used by previous investigators.

The informed condition. After the interview and a 5-min rest period, the subjects in this and in subsequent experiments were shown the same sequence of five figures under the same procedures and for the same time intervals as in the earlier uninformed presentation. During this second presentation, the subjects were, of course, aware of the reversibility (and the alternatives) of the critical figure.

Subjects. Since knowledge about reversible figures in general and about the particular critical figures used in these experiments can derive from experience in daily life, as well as from laboratory instructions, high school students were deliberately chosen as subjects. It was intended that this would decrease but of course not entirely eliminate the probability of prior exposure to such figures. In all of the experiments, the subjects were 20 volunteer high school students.

\section{Results}

The order in which a critical figure (fourth or fifth) appeared in the sequence produced no effect. Results for each figure will, therefore, be reported 
for this and subsequent experiments as being based on an $\mathrm{N}$ of 20 .

The results are shown in the first row of Table 1. It will be noted that only results for the vase-face figure are given. The reason for this is that it proved impossible to judge whether or not reversal had occurred to the Necker cube, since descriptions of either alternative (in the absence of explicit instructions concerning how to describe them) were apt to be identical, for example "box." However, the absence of any comments by many subjects indicating a change (e.g., "Oh, now I see the different box" or "Now I see a box tilted differently"), and the confirmation of this in the interview, does indicate that a majority did not reverse at all in viewing the Necker cube under the Uninformed condition. Because of the difficulty with this figure, we used a somewhat different reversible perceptual figure in the remaining experiments. It is, of course, precisely this type of difficulty which has led to the use of fully instructed subjects in the previous research done in this area.

As for the vase figure, $55 \%$, or 11 out of the 20 subjects, never reversed during the $30-\mathrm{sec}$ exposure period in the Uninformed condition. In the Informed condition, all 20 of these subjects did reverse. Tables 1 and 2 also indicate that in the Informed condition, the subjects reversed early; all 20 reported a reversal by the third signal, the average reversal report occurring on Trial 1.25. Those nine subjects in the Uninformed condition who did reverse tended to do so in response to the later signals, six of the nine reporting their first reversals to one of the last three signals. Reversals also occurred frequently in the Informed condition. During the six-signal interval of $30 \mathrm{sec}$, there was an average of 4.25 responses reporting a reversal. In the Uninformed condition, however, there was an average of only .55 reversal responses reported.
This pattern of approximately half of the subjects failing to reverse in the Uninformed condition, with few and late reports for those who did reverse, remained a consistent one in the following experiments. The early and frequent reversals reported in the Informed condition is of course typical of the phenomenon reported in the previous investigations that used instructed subjects.

\section{EXPERIMENT 2}

\section{Method}

Because of the difficulty in using the Necker cube, and the desire to include a figure that reverses its perspective in the research, Experiment 1 was replicated with the substitution of a newly designed figure for the cube (see Figure 1). This figure may be seen either as a truncated pyramid or as a box or hallway. Thus, it was presumed that the two very different perceptions that were possible would lead to appropriate and easily distinguishable descriptions by the subjects. All procedures for the Informed and Uninformed conditions were the same as in Experiment 1 . However, now the subjects were asked to participate in a third condition immediately after having completed the first two conditions. This third condition was a Free-Responding condition. The subjects were exposed to the same figures for the same periods of time, but no signals were presented. The subjects were instructed to report verbally when, and only when, they experienced a change in perception. If there was no change, the subject was not to respond. All responses were recorded on tape and subsequently transcribed. Obviously, this third Free Responding condition was an Informed condition. It was intended to supply additional data with which to evaluate the data obtained with the Informed sampling procedure.

\section{Results}

The data for the vase-face figure in the Informed and Uninformed free sampling conditions are highly similar to those obtained in Experiment 1. (see Tables 1 and 2). For example, 10 of the 20 subjects did not reverse in the Uninformed condition. In the Informed condition, all 20 subjects had reversed by the second signal. The Uninformed sampling condi-

Table 1

Mean First Reversal and Mean Number of Reversals

\begin{tabular}{|c|c|c|c|c|c|c|c|c|c|}
\hline \multirow{3}{*}{$\begin{array}{c}\text { Experi- } \\
\text { ment }\end{array}$} & \multirow{3}{*}{$\begin{array}{c}\text { Duration } \\
\text { (Seconds) }\end{array}$} & \multirow[b]{3}{*}{ Figure } & \multirow{2}{*}{\multicolumn{2}{|c|}{$\begin{array}{c}\text { Mean Trial on Which First } \\
\text { Reversal Was Reported } \\
\text { Sampling Condition }\end{array}$}} & \multicolumn{3}{|c|}{$\begin{array}{l}\text { Mean Number of } \\
\text { Reversals Reported }\end{array}$} & \multicolumn{2}{|c|}{$\begin{array}{l}\text { Percentage of } \\
\text { Subjects Who } \\
\text { Never Reversed }\end{array}$} \\
\hline & & & & & \multicolumn{2}{|c|}{ Sampling Condition } & \multirow{2}{*}{$\begin{array}{l}\text { Informed } \\
\text { Free } \\
\text { Responding }\end{array}$} & Unin- & \\
\hline & & & Uninformed & Informed & Uninformed & Informed & & formed & Informed \\
\hline 1 & 30 & Vase-Face & 5.0 & 1.25 & .55 & 4.25 & & 55 & .0 \\
\hline 2 & 30 & $\begin{array}{l}\text { Vase-Face } \\
\text { Pyramid-Hallway }\end{array}$ & $\begin{array}{l}4.2 \\
3.9\end{array}$ & $\begin{array}{l}1.1 \\
1.55\end{array}$ & $\begin{array}{l}1.2 \\
1.5\end{array}$ & $\begin{array}{l}3.85 \\
3.40\end{array}$ & $\begin{array}{l}6.9 \\
7.4\end{array}$ & $\begin{array}{l}50 \\
35\end{array}$ & $\begin{array}{l}.0 \\
.0\end{array}$ \\
\hline 3 & 60 & $\begin{array}{l}\text { Vase-Face } \\
\text { Pyramid-Hallway }\end{array}$ & $\begin{array}{l}8.5 \\
7.4\end{array}$ & & $\begin{array}{l}2.4 \\
2.35\end{array}$ & & $\begin{array}{l}9.1 \\
9.1\end{array}$ & $\begin{array}{l}55 \\
50\end{array}$ & \\
\hline 4 & 180 & $\begin{array}{l}\text { Vase-Face } \\
\text { Pyramid-Hallway }\end{array}$ & $\begin{array}{l}17.6 \\
14.9\end{array}$ & $\begin{array}{l}2.65 \\
3.3\end{array}$ & $\begin{array}{l}8.5 \\
9.75\end{array}$ & $\begin{array}{l}15.6 \\
17.0\end{array}$ & & $\begin{array}{l}35 \\
35\end{array}$ & $\begin{array}{l}.0 \\
.0\end{array}$ \\
\hline
\end{tabular}

Note-Subjects who did not reverse at all were arbitrarily assigned a score equivalent to the last signal, i.e., 6 in Experiment 1,12 in Experiment 3, and 36 in Experiment 4. Thus, in the Uninformed condition, first reversals appear to occur on later trials as the duration of the experiment is increased. This arbitrary assignment was made in order to maintain the equal Ns for both conditions by not discarding the nomreversing subjects. Had only the reversing Uninformed subjects been included, a misleading score would have resulted. 
Table 2

Trial On Which First Reversal Was Reported During Sampling Procedures

\begin{tabular}{|c|c|c|c|c|c|c|c|c|c|c|c|c|c|c|c|c|c|c|}
\hline \multirow{3}{*}{$\begin{array}{c}\text { Experi- } \\
\text { ment }\end{array}$} & \multirow{3}{*}{$\begin{array}{c}\text { Stimulus } \\
\text { Figure }\end{array}$} & \multirow[b]{3}{*}{ Condition } & \multicolumn{15}{|c|}{ Number of Subjects Whose First Reversal Occurred at Indicated Signal } & \multirow{3}{*}{$\begin{array}{c}\text { Total Subjects } \\
\text { Who Reversed } \\
(\mathrm{N}=20)\end{array}$} \\
\hline & & & Signal & 1 & 2 & 3 & 4 & 5 & 6 & 7 & 8 & 9 & 10 & 11 & 12 & $13-24$ & $25-36$ & \\
\hline & & & Time* & 5 & 10 & 15 & 20 & 25 & 30 & 35 & 40 & 45 & 50 & 55 & 60 & $65-120$ & $125-180$ & \\
\hline 1 & $\mathrm{v}$ & $\begin{array}{l}\text { U } \\
\text { I }\end{array}$ & & $\begin{array}{r}2 \\
16\end{array}$ & $\begin{array}{l}1 \\
3\end{array}$ & $\begin{array}{l}0 \\
1\end{array}$ & 1 & 4 & 1 & & & & & & & & & $\begin{array}{r}9 \\
20\end{array}$ \\
\hline 2 & $\mathbf{v}$ & $\begin{array}{l}\text { U } \\
\text { I }\end{array}$ & & $\begin{array}{r}5 \\
18\end{array}$ & $\begin{array}{l}1 \\
2\end{array}$ & 1 & 1 & 2 & 0 & & & & & & & & & $\begin{array}{l}10 \\
20\end{array}$ \\
\hline 2 & $\mathbf{P}$ & $\begin{array}{l}\text { U } \\
\text { I }\end{array}$ & & $\begin{array}{r}5 \\
13\end{array}$ & $\begin{array}{l}2 \\
4\end{array}$ & $\begin{array}{l}1 \\
2\end{array}$ & $\begin{array}{l}3 \\
1\end{array}$ & 0 & 2 & & & & & & & & & $\begin{array}{l}13 \\
20\end{array}$ \\
\hline 3 & $\begin{array}{l}\mathrm{V} \\
\mathrm{P}\end{array}$ & $\begin{array}{l}\mathrm{U} \\
\mathrm{U}\end{array}$ & & $\begin{array}{l}4 \\
4\end{array}$ & $\begin{array}{l}1 \\
2\end{array}$ & $\begin{array}{l}0 \\
2\end{array}$ & $\begin{array}{l}1 \\
0\end{array}$ & $\begin{array}{l}0 \\
0\end{array}$ & $\begin{array}{l}0 \\
0\end{array}$ & $\begin{array}{l}0 \\
2\end{array}$ & $\begin{array}{l}0 \\
0\end{array}$ & $\begin{array}{l}2 \\
0\end{array}$ & $\begin{array}{l}1 \\
0\end{array}$ & $\begin{array}{l}0 \\
0\end{array}$ & $\begin{array}{l}0 \\
0\end{array}$ & & & $\begin{array}{r}9 \\
10\end{array}$ \\
\hline 4 & $\mathbf{v}$ & $\begin{array}{l}\text { U } \\
\text { I }\end{array}$ & & $\begin{array}{r}4 \\
13\end{array}$ & $\begin{array}{l}2 \\
2\end{array}$ & $\begin{array}{l}0 \\
2\end{array}$ & $\begin{array}{l}0 \\
0\end{array}$ & $\begin{array}{l}1 \\
2\end{array}$ & $\begin{array}{l}0 \\
0\end{array}$ & $\begin{array}{l}2 \\
0\end{array}$ & $\begin{array}{l}1 \\
0\end{array}$ & $\begin{array}{l}0 \\
0\end{array}$ & $\begin{array}{l}0 \\
0\end{array}$ & $\begin{array}{l}0 \\
0\end{array}$ & $\begin{array}{l}0 \\
0\end{array}$ & $\begin{array}{l}2 \\
1\end{array}$ & 1 & $\begin{array}{l}13 \\
20\end{array}$ \\
\hline 4 & $\mathbf{P}$ & $\begin{array}{l}\text { U } \\
\text { I }\end{array}$ & & $\begin{array}{r}3 \\
12\end{array}$ & $\begin{array}{l}6 \\
2\end{array}$ & $\begin{array}{l}0 \\
2\end{array}$ & $\begin{array}{l}1 \\
1\end{array}$ & $\begin{array}{l}0 \\
1\end{array}$ & $\begin{array}{l}0 \\
0\end{array}$ & $\begin{array}{l}0 \\
0\end{array}$ & $\begin{array}{l}0 \\
0\end{array}$ & $\begin{array}{l}2 \\
0\end{array}$ & $\begin{array}{l}1 \\
0\end{array}$ & $\begin{array}{l}0 \\
0\end{array}$ & $\begin{array}{l}0 \\
0\end{array}$ & $\begin{array}{l}0 \\
2\end{array}$ & 0 & $\begin{array}{l}13 \\
20\end{array}$ \\
\hline
\end{tabular}

Note $-V=$ vase-face figure, $P=$ pyramid-hallway figure, $U=$ uninformed sampling condition, $I=$ informed sampling condition.

*Seconds

tion resulted in a mean of 1.2 reversals being reported. This number increases to 3.85 for Informed Sampling, and then increases to an average of 6.9 reversals reported in the Free Responding condition. This would suggest that the sampling procedure of tapping every $5 \mathrm{sec}$ might miss some reversals that occur during the interval between taps. Since these reversals occur more often in the Informed condition, the result would tend to be a greater underestimation of reversals during Informed Sampling than during Uninformed Sampling, and would therefore be a bias toward decreasing the difference in results between the two conditions.

The pyramid-hallway figure also revealed a similar pattern. Table 2 indicates that all of 20 subjects in the Informed condition reported a reversal by the fourth signal, with 13 having reversed on the first signal. In the Uninformed condition, 7 (or 35\%, Table 1) never reported a reversal. This percentage of nonreversals is lower than that obtained for the vaseface figure in both experiments, and is lower than the percentage of $50 \%$ for the pyramid figure ob:
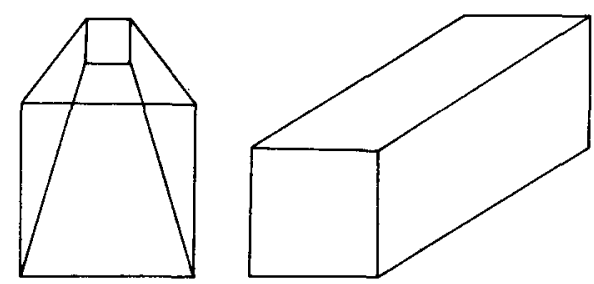

B.

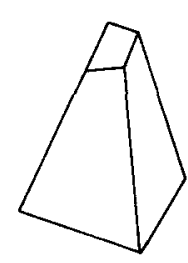

C.
Figure 1. The ambiguous pyramid-hallwa! figure used in Experiments 2, 3, and 4 . Figure $A$ is the ambiguous version, and $B$ and $C$ are the unambiguous versions. tained in the next experiment for an equivalent $60-\mathrm{sec}$ period of time. However, in this experiment, there were 6 subjects who reversed in the Uninformed condition from a three-dimensional perception (pyramid) to a two-dimensional figure (squares ... lines), but did not perceive the alternative perspective. Thus, the percentage of Uninformed subjects who do not report a perspective reversal is $65 \%$.

\section{EXPERIMENT 3}

The previous two experiments had shown that about half of the Uninformed subjects did not experience reversals within $30 \mathrm{sec}$. Experiment 3 was designed to investigate this phenomenon for the longer period of $60 \mathrm{sec}$.

\section{Method}

All procedures were the same as in the previous experiments except for two changes. First, the critical figures (vase and pyramid) were each exposed for $60 \mathrm{sec}$, or one initial signal plus 12 subsequent taps. Second, after a 5-min postinterview rest interval, all subjects participated in the Informed Free Responding procedure for $60 \mathrm{sec}$ for each of the critical figures. Thus, no Informed Sampling procedure was used. It was decided to use Free Responding as the only control in this experiment because it was possible that the Free Responding procedure in Experiment 2 might have been contaminated by the Informed Sampling that immediately preceded it. This possibility was therefore eliminated in Experiment 3 .

\section{Results}

The major finding was replicated for a 1-min exposure interval. Approximately $50 \%$ of the subjects did not reverse despite the doubling of the exposure time.

In the Uninformed condition, 11 of the 20 subjects did not reverse to the vase-face figure, and 10 of the 20 did not reverse to the pyramid-hallway figure. 
Of these subjects, 6 did not reverse to either critical figure, and of course 4 more did not reverse to the pyramid and 5 other subjects did not reverse to the vase. Thus, 15 of the 20 subjects did not reverse to at least one of the critical figures during its $60 \mathrm{sec}$ of exposure.

The extra $30 \mathrm{sec}$ of exposure had very little effect on the rate of reversals. Table 2 reveals that at the end of $15 \mathrm{sec}, 8$ subjects in the Uninformed condition had reversed while viewing the pyramid. In the $45 \mathrm{sec}$ that followed, only 2 out of the remaining 12 subjects reported a reversal. Similarly, 6 of the 9 Uninformed subjects who did reverse to the vase had done so by the fourth signal, i.e., within $20 \mathrm{sec}$. Thus, if one assumes a satiation-type model for perceptual reversals, these data would suggest that the satiation is close to an asymptote at about 20 to $30 \mathrm{sec}$. Nevertheless, the question is raised concerning the possible effect of even longer exposure times on reversals in the Uninformed condition.

\section{EXPERIMENT 4}

\section{Method}

The fourth experiment was basically a replication of Experiment 2, with an increase of exposure time from 30 to $180 \mathrm{sec}$, and the use of only the Uninformed and Informed Sampling procedures.

\section{Results}

Again, the results are consistent with those of the previous experiments, even with the extended exposure time. Table 2 indicates that with Uninformed viewing of the vase-face figure, $50 \%$ of the subjects had not reversed at the end of $1 \mathrm{~min}, 40 \%$ had not reversed at the end of another minute of viewing, and at the end of 3 minutes of viewing, $35 \%$ had not yet reversed. In viewing the pyramidhallway figure, half of the subjects did not reverse within $40 \mathrm{sec}, 3$ more subjects did reverse at the next two signals, and then none of the remaining 7 subjects reversed during the subsequent $130 \mathrm{sec}$ of viewing time. This is consistent with the conclusion arising from Experiment 3, namely that in the Uninformed condition most of the reversals will have occurred within 30 to $40 \mathrm{sec}$. In the Informed condition, over half the subjects will report a reversal as a response to the very first signal (see Table 2).

The average number of reversals for both figures continued to be about twice as high in the Informed condition as in the Uninformed condition, about 16 in $3 \mathrm{~min}$ (Informed) as compared to about 9 in $3 \mathrm{~min}$ for the Uninformed condition.

\section{DISCUSSION}

The finding that approximately half of our subjects, in the Uninformed condition, failed to reverse to an ambiguous stimulus, has both methodological and theoretical implications. The new methodology alters the nature of the phenomenon under discussion, and indicates that previous methods have confounded the behavior that they were designed to investigate. The failure to obtain spontaneous reversals also presents difficulties for currently popular theoretical explanations of perceptual reversals, such as satiation models.

Several possible criticisms of the new Uninformed Sampling method may be raised. For example, it may be suggested that some of the nonreversing subjects actually might have experienced a reversal during the interval between the 5 -sec signals. This reversal would then not have been reported and the subject would have been mistakenly scored as a nonreverser.

It is also possible to argue that a subject in the Uninformed condition reversed one or more times but simply did not report it because the instructions did not make it sufficiently clear that such a percept and change was the kind of thing to report. It is for reasons similar to this that great care and importance was placed on the interview procedure. Each subject was asked, "Did you see anything other than the face (vase, pyramid, etc.) that you reported?" Then each subject was asked, while being shown the unambiguous version of the nonreported perceptual alternative, "Did you see anything that looked like this?" Any reply during the interview that suggested a perceived reversal of any type, caused that subject to be counted as a reversing subject. This criterion was a very conservative one, and, thus, the combination of sampling plus interview procedures resulted in a tendency, if anything, to underestimate the number of nonreversing subjects, rather than a tendency to miss a reversing subject.

Our instructions permitted the subject either to maintain or to change his responses while viewing the experimental figures. Two figures, a circle and a square, were included as part of the experimental sequence on the assumption that these figures would not lend themselves to varying responses, and would therefore demonstrate to the subject that it was appropriate to have a continuing response to some of the stimuli. It may be suggested that this procedure may have actually produced a set not to reverse or alter responses. It should be recalled, however, that the next figure in the sequence was the "snowman," which did lend itself to variations in response, thus counteracting any set not to alter responses. Furthermore, these figures appeared in all conditions, and it is clear that a set not to reverse was not apparent in the Informed condition. In fact, the instructions that were used did encourage the subject to report changes (i.e., "on the first tap I might say ... but on the next tap it might look like ..."); he simply was not instructed to expect a particular type of change. Finally, it is not clear from the viewpoint 
of a satiation model how a set not to reverse, even if present, could affect the automatic build up of cortical resistance that is said to occur while viewing the figure.

In the Uninformed condition of all our experiments, we have indicated that "traditional" results are not obtained. It may be claimed that only half of our experiments used a traditional figure, the "Rubin vase-face," and that perhaps we should not have expected traditional results with a new figure such as the pyramid-hallway (see Figure 1). However, Table 1 clearly indicates that in the Informed Free Responding and Informed Sampling conditions subjects respond to both the vase-face figure and the pyramid figure in a very similar manner. As an example, in Experiment 4, with 3 min of viewing time in the Informed Sampling condition, there was an average of 15.6 reversals reported for the vase-face, and an average of 17.0 reversals reported for the pyramid-hallway. In the Informed Free Responding condition of Experiment 3, both figures yielded an identical average of 9.1 reversals in $30 \mathrm{sec}$. Thus it may be concluded that the failure to reverse in the Uninformed condition was not peculiar to the pyramid figure but is a more general result.

In our present experiments, high school students were used as subjects. Previous data had indicated that a college population was generally too experi enced with this type of material and would not be naive in the Uninformed condition, as desired. This leads to the inference that if a still younger and therefore more naive sample had been used, the percentage of spontaneous reversals would have been even lower. Some pilot work that we have performed with adults who were not educated in American schools also suggests a high level of nonreversers. We are inclined to believe at present that perhaps even the high school population may be too sophisticated and that this may account for the half of our subjects who did reverse; such a conclusion seems more plausible than the alternative one that half of the population spontaneously reverse even under an Uninformed procedure and half do not. We are, therefore, inclined to give our findings the strong interpretation that with the appropriate level of naivete, there is essentially no reversing to the kind of reversible figures sampled in our study.

Generally, spontaneous reversal has been taken to mean that an ambiguous figure will automatically and quickly alternate. It is now clear that this will occur only if the subject knows about the alternatives, and this is a new interpretation of the meaning of spontaneous reversal. It is curious that although knowledge of the alternative perceptions will produce frequent reversals, it still does not place the reversal entirely under voluntary control. Thus the reversal remains more or less spontaneous in the sense of being nonvoluntary, but not in the sense of occurring with Uninformed subjects. It is known that voluntary attempts can influence the rate of reversals (Pelton \& Solley, 1968), but it has not been reported that voluntary control can keep an ambiguous figure from reversing entirely. Thus, the precise process by which knowledge of reversibility has its effect needs further research.

For example, the relative role of knowledge of reversibility as compared to knowledge of the alternative remains to be clarified. We may note that there was no trend for subjects who had reversed to the first of the critical figures, in the Uninformed condition, to then also reverse to the second critical figure. Thus, under these conditions, knowledge of reversibility, produced by having experienced a reversal with a prior stimulus, was not of consequence in producing subsequent reversals to new figures. Nevertheless, experience with reversible figures in general does seem to make a college population too sophisticated to qualify as truly naive or Uninformed subjects. It is clear that clarification is needed on this question of different types of knowledge, and its possibly differential effects on reversal behavior. We have initiated experiments in which subjects are variously informed as to the nature of the ambiguous material with which they are presented.

These results are not consistent with a satiation or fatigue type of theory, which is the currently most dominant explanation for reversals. About half of our subjects experienced reversals, and it is difficult to conceive of a neural fatigue model that is applicable to only half the population.

The evidence in the literature for satiation theories appears to be of two types. First, there are the reported direct effects on the perception of ambiguous figures as a result of prior "satiation" by unambiguous viewing (Carlson, 1953; Hochberg, 1950). Second, there is the reported indirect effect of increase in reversal rate as viewing time increases (e.g., Brown, 1955).

It should be noted, however, that all of these experiments have used Informed subjects and thus it is quite possible that once again the results have been confounded by the technique of previously informing the subjects of the perceptual alternatives. In our laboratory, we have replicated the direct effect paradigm by having a subject first view an unambiguous alternative and then presenting him with the relevant ambiguous drawing. Subjects were then shown drawings that represented the various alternative ways of perceiving the ambiguous figure and were asked to indicate which alternative was most like the previous (ambiguous) drawing that they had just viewed. This procedure allowed the subjects to remain uninformed as to perceptual ambiguity throughout the experiment. In this case, the 
phenomena appear to be more complex than anticipated, and at this point the data are not capable of either supporting or rejecting simple satiation models.

Moreover, as to the indirect evidence, while performing our experiments, in the Informed Free Responding condition, we have not obtained strong or consistent trends toward increased reversal rates as viewing progressed. In instances when we have obtained some trends of this type, they are revealed only when group data are averaged over time intervals. These averages then suggest a group trend toward increased reversal rate, that is not apparent for any single subject taken separately. However, under the conditions of these experiments, many subjects do not reverse at all until the later intervals, and thus more reversals are reported in the later intervals. Therefore, an increase in the number of subjects who are reversing gives the mistaken impression of an increase in rate of reversal for all subjects.

Similarly, if the rate of reversals was increasing during viewing periods, then there should be a steady shortening in the duration of subsequent perceptions, with each alternative being perceived for briefer periods. Thus, in a Free Responding condition, there should be a large preponderance of times when a preceeding perception lasted longer than its immediately following perception. In the present experiments, only Experiment 3 has a Free Responding condition with a viewing duration that lasted as long as $1 \mathrm{~min}$. It should also be noted, that in this condition the subjects were now fully informed. Using group data, one of the figures, the pyramidhallway, showed a continuing increase in reversal rate for the $1 \mathrm{~min}$ exposure interval. The other figure, the vase-face, showed an increasing reversal rate for the first $15 \mathrm{sec}$, but then decreased steadily for the remaining $45 \mathrm{sec}$.

An analysis was made of the temporal lengths of all perceptions that terminated within the 60-sec interval. These intervals were compared to the lengths of the next succeeding interval to see if the second interval was shorter, longer, or equal to the first. The number of shorter second intervals, $41 \%$ for the cube and $44 \%$ for the vase-face, was only slightly more than the number of longer second intervals, $39 \%$ for the cube and $\mathbf{4 0 \%}$ for the vase-face. This pattern, see Table 3 , was very similar for both figures, despite the fact that one figure had an increasing reversal rate and the other had a decreasing rate of reversal. These data suggest that the previous indirect evidence for fatigue theory that stems from the apparent increase in the speed of alternation may require further consideration. It is possible that an analysis of this type would have been more appropriate and would have indicated that, in fact, reversals
Table 3

Comparative Distributions of the Durations of Contiguous Intervals During Reversal

\begin{tabular}{cccc}
\hline & \multicolumn{3}{c}{$\begin{array}{c}\text { Comparative Length of } \\
\text { the Second Interval }\end{array}$} \\
\cline { 2 - 4 } Figure & Shorter & Longer & Same \\
\hline Pyramid-Hallway & $41 \%$ & $39 \%$ & $20 \%$ \\
Vase-Face & $44 \%$ & $40 \%$ & $15 \%$ \\
\hline
\end{tabular}

Note-These data are for the 20 subjects in the Free-Responding condition of Experiment 3.

may not tend to occur with greater frequency as viewing continues.

A finding and conclusion similar to ours has also been reported by Sadler and Mefferd (1970). They were investigating the durations of alternate percepts to the Necker cube and the duck-rabbit figure. They found that their individual subjects did not show decreasing intervals of perceptions, and they concluded that "when the results for the successive intervals are averaged across subjects, the smoothed curve becomes misleading if one extrapolates from this group behavior to individual behavior and attributes the resulting apparent regularity of intervals to a basic process that is regular and systematic [such as] satiation."

In conclusion, the present experiments indicate that reversals do not normally occur easily or rapidly. They do so only in certain conditions, such as when the subject is informed as to the alternatives. But then the problem becomes one of explaining why they do occur at all under these conditions. Since a plausible belief would be to expect that once a perceptual organization was achieved, a parsimonious perceptual system would attempt to maintain that organization, the fact that reversal occurs at all under any condition remains a problem.

\section{REFERENCES}

Brown, K. T. Rate of apparent change in a dynamic ambiguous figure as a function of observation time. American Joumal of Psychology, 1955, 68, 358-371.

Carlson, V. R. Satiation in a reversible perspective tigure. Journal of Experimental Psychology. 1953, 45, 442-448.

HoснвеRg, J. E. Figure ground reversal as a function of visual satiation. Journal of Experimental Psychology, 1950, 40, 682-686.

Kohler, W., \& Wallach, H. Figural after effects. An investigation of visual processes. Proceedings of the American Philosophical Society, 1944, 88, 269-357.

Pelton. L. H., \& Solley, C. M. Acceleration of reversals of a Necker cube. American Journal of Psychology, 1968, 81, 585-589.

SADler, T. G., \& MefFerd, R. B. Fluctuations of perceptual organization and orientation. Perceptual and Motor Skills, 1970. 31. $739-749$.

(Received for publication February 28, 1977; revision accepted August 26. 1977.) 